Bulgarian Academy of Sciences. Space Research and Technology Institute.

Aerospace Research in Bulgaria. 31, 2019, Sofia

DOI: https://doi.org/10.3897/arb.v31.e06

\title{
INVESTIGATION OF THE SIMILARITY ALGORITHM OF THE SATELLITE IMAGES STORAGE SYSTEM FOR STABILITY ON THE BASIS OF HAAR WAVELETS ACCORDING TO TIKHONOV
}

\author{
Maretta Kazaryan $^{1}$, Mikhail Shahramanian ${ }^{2}$, Svetoslav Zabunov ${ }^{3}$ \\ ${ }^{1}$ North Ossetian State Medical University, marettak@bk.ru \\ ${ }^{2}$ Research Institute "AEROKOSMOS", 7283963@mail.ru \\ ${ }^{3}$ Space Research and Technology Institute - Bulgarian Academy of Sciences, \\ e-mail: svetoslavzabunov@gmail.com
}

\begin{abstract}
Key words: Wavelet-Haar transformations, The Tikhonov regularization method, Waste disposal facilities (WDF), Waste disposal site (WDS).
\end{abstract}

\begin{abstract}
A model of the automated space monitoring system (ASMS) for the presence of waste disposal facilities (WDFs) is being developed in this paper. One of the components of the model is the space imagery storage unit, which allows not only to improve the performance of environmental authorities, but also to enhance the effectiveness of WGF monitoring (space, aerological, and ground based). The article also investigates the problem of searching in space image archives of similarities based on Haar wavelet transformations for stability.

This paper aim at modelling of an ASMS and the application of the regularization method in the problem of finding similar space images in the archives of the simulated ASMS by means of discrete orthogonal transformations, in particular, wavelet transformations of Haar. We use the Tikhonov regularization method, elements of mathematical analysis, the theory of discrete orthogonal transformations, and methods for decoding cosmic images.

The result of the experiment, which confirms the Tikhonov regularization method for Haar wavelet transforms, based on the example of processing archive satellite images that are located in a data warehouse, is presented.
\end{abstract}

\section{Introduction}

In relation to the emergence of a variety of information technologies with their numerous capabilities, wide-range monitoring has been provided for a variety of phenomena and, accordingly, objects [1-9]. It is, first of all, the satellite systems of Earth observation and large flows of information entering the scientific laboratories. This led to the creation of new approaches and methods of organizing 
the work with information on remote sensing of the Earth (RSE), as well as the technologies for remote monitoring systems construction.

The major factors in the field of remote sensing that affect the development of monitoring systems are:

- Growth of the number of spacecraft, resulting in increased frequency and volume of information that can be utilized by the systems. It is now possible to organize monitoring of rapidly occurring processes.

- A large number of satellite systems are now equipped with modern technology that allows the research of quantitative information calibration of the phenomena and objects on Earth.

- The information is quite accessible, and this leads to its extensive use.

- The availability of remote sensing information has identified the need to increase the level of automation of satellite information processing and work with extremely large data archives.

- Data processing systems need to be optimized, forming basic information products and performing standard primary processing. The implementation of these procedures requires considerable computing resources.

- Effective work with extremely large archives and, accordingly, computing resources leads to the creation of new technological capabilities.

- To perform all the listed tasks, one must use various distributed computing resources.

In this paper, studies are carried out in the field of waste disposal facilities (WDFs), which will be considered while creating a specific remote monitoring system.

WDFs are a source of risk, associated with air and soil pollution, and pose a real threat to the population and the environment [10-12].

"The big business gurus bequeathed to their descendants: the most profitable investment is an investment in a person's natural needs. Among other things, a person in the process of his life leaves behind mountains of debris. Only the population of our country annually "produces" 35-40 million tons of solid domestic waste"1.

It is almost impossible to control these objects, scattered on a giant territory, by means of traditional land-based methods, and the annual use of aerial observations becomes more and more expensive and can be carried out only in limited local areas. Under these conditions, there is no alternative to space

\footnotetext{
${ }^{1}$ http://www.rbc.ru/economics/23/08/2012/5703fbc99a7947ac81a6b045
} 
monitoring as the most expeditious and cheap method for detecting and controlling the development of unauthorized places for the WDFs.

The current article initiates a project on the creation of an automated space monitoring system for the presence of WDFs in the territory of the Russian Federation designed to provide an operative survey of the study area, the detection and mapping of real and potential centres of unauthorized landfills, the forecast of their development, a preliminary assessment of the scale of disasters and possible consequences. It should be emphasized that such systems belong to the class of open systems. They cannot be built in a complete form, they are in constant development.

The initial project envisages the creation of a starter complex (core) of the system, including the space and ground segments. An effective monitoring system should comprise a space segment: spacecraft on circular solar synchronous orbits equipped with active and passive sounding instruments of different spatial resolution in the widest possible range of the electromagnetic spectrum. First of all, it is advisable to use such public space systems such as NOAA (resolution $1100 \mathrm{~m}$ ) and EOS AM TERRA (resolution $250 \mathrm{~m}$ ) for regular survey of state territory. Of the high-resolution systems, the meteorological data "Meteor-3M" (37 m resolution) and Indian satellites IRS 1C/1D (PAN resolution $5.6 \mathrm{~m}$ ) are the most accessible. It is these spacecraft that form the backbone of the space segment of the system.

Since the research area is often restricted by a strong cloud cover, which prevents regular space surveys in the microwave range, it is necessary to use active sounding data, in particular, the Canadian satellite RadarSat-1, and Sentinel-1 (Copernicus). This satellite is equipped with radar, which allows obtaining highquality images of the Earth's surface, regardless of the presence of cloud cover and time of day with a resolution of 8 to $100 \mathrm{~m}$. In combination with space imagery in the visible and thermal ranges, this information is extremely useful for detecting and monitoring the development of unauthorized waste disposal facilities [9]. The basis of the ground segment infrastructure of the ASMs WDF is the remote sensing data acquisition system (RSAS). The most reasonable solution is to create duplicate universal receiving stations and a distributed network for processing space images. Creation of integrated automated WDF monitoring systems that unite informational modelling and control systems, software complexes and technical means of data collection and transmission on the basis of local computer networks into a single structure, and the development of perspective models and algorithms for forecasting foci, unauthorized WDF is an actual problem.

The functioning of space monitoring of waste disposal facilities (WDFs) can be represented using the following scheme (Fig. 1). 


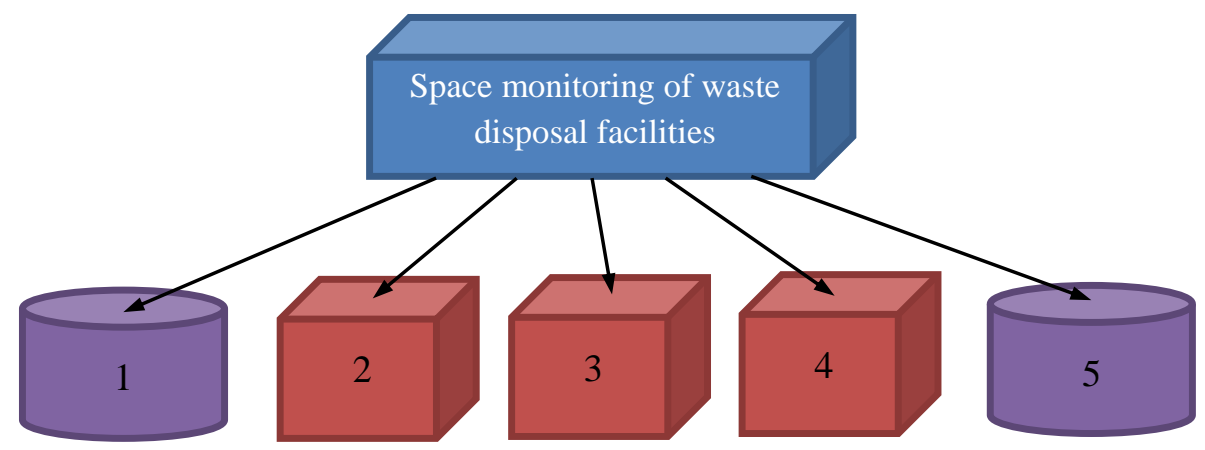

Fig. 1. Block diagram of WDF space monitoring

In Fig. 1 the blocks are:

1. Database of existing polygons of WDF, which are listed in the state register of solid domestic waste $(\mathrm{SDW})^{2}$ for the current time;

2. A subsystem for detecting unauthorized $\mathrm{WDF}^{3}$ at the current time;

3. A subsystem for monitoring the rules for the design, operation and reclamation (DOR) of existing solid waste landfills $[1,2,10]$;

4. A subsystem for estimating the parameters of the WDF and their environmental impact $[2,11,12]$;

5. Subsystem of satellite monitoring.

The WDF space monitoring system functions as follows. In block II, space images are processed by means of automation of cosmic image processing in conjunction with detection of $\mathrm{WDF}^{4}$. Comparing the detection area of the WDF with the data of the database of solid waste landfills in block I, unauthorized WDFs are detected, and fixed in block II. In block IV, the WDF parameters are evaluated for both the WDF presented in Block I and the unauthorized WDFs presented in Block II. Using the data from Block V obtained through satellite monitoring methods, the data of Block I and IV is collected in Block III. There, the incoming information is further analysed, and violations of operating rules are identified for existing landfills and the development of appropriate environmental measures.

The proposed monitoring system for landfills and WDFs (Fig. 1), developed on the principle of extraterritoriality, allows the control the garbage storage sites to be taken to a new information level.

\footnotetext{
${ }^{2}$ http://www.airsoft-bit.ru/stati-po-ekologii/394-groro

${ }^{3} \mathrm{http} / / /$ www.ecobiocentre.ru/naturalist/google-svalka.doc

${ }^{4}$ https://cyberleninka.ru/article/n/metodika-avtomaticheskogo-detektirovaniya-komponent-obektovzahoroneniya-othodov-po-kosmicheskim-izobrazheniyam
} 
In addition to the above described system, it is possible to consider the creation of a system for supporting long-term data archives ${ }^{5}$ along with and its information input. These systems are actively created in recent years to address both fundamental and applied problems. The main task of such systems is to collect and organize long-term data storage and to conveniently represent this data (import this data) into the information systems of various research projects.

We will consider the use of ready-made software for storage, output and input of monitoring data as an alternative to creating software for such systems. The most important thing of the inner workings of such systems is the electronic Earth's map of the site on Earth being under research. The electronic map has a primary interface, it identifies the objects that are of interest to us, in this case, these are solid waste objects, authorized and unauthorized, and sampling points, through which soil survey is carried out, etc. The operation of the system will look like this: some kind of GIS-system with open source. Then the map and data are loaded into it.

The drawback of this approach is that GIS systems are either not adapted to Russian or this is done poorly. This disadvantage introduces some discomfort in the process of work, so it is advisable for one to conduct their own development of ASMS SWF. When creating such an information system, you must have the following components at hand: database management systems, a web server, a programming language development environment and, of course, a web browser.

The question of obtaining an electronic map can be solved in two ways. The first one is to use Yandex Maps or Google Maps services. You can optionally download the map fragment of interest in a raster format and convert it to a vector format, so you can create an interactive map, for example, using the Inkscape application. This method has certain specificity - in spite of a fairly simple manufacturing method, such a map does not provide information on the composition of the soil of the investigated section of the earth.

The second method is the use of specialized maps on paper. Complete information is provided, including soil data, etc. One could scan such maps and convert them to vector format. However, this approach seems rather cumbersome due to the fact that paper maps are not always in good condition and special computer programs for their improvement have to be applied.

Thus, summarizing the above reasoning, we may conclude that for storing and processing of the earth monitoring data, it is possible to adapt applications to the tasks, leading to a significant reduction in time.

\footnotetext{
${ }^{5}$ http://www.ntsomz.ru/ks_dzz/nkpoi/catalog_service
} 
The next block on the information stream is the block for image processing, i.e. space images ${ }^{6,7}$. With the widespread implementation of digital communication systems, the urgency of recovery problems solving, reduction of additive noise and reconstruction of multidimensional signals, obtained with photo and video cameras and transmitted through communication channels, is increasing $^{8}$. In practice, the images are often distorted by noise, which happens during the formation and transmission of signals through the communication channel. When digital images are obtained, the noise source can be a CCD detector-spectrometer, as well as fluctuation processes in photo sensors ${ }^{9}$. The results of image restoration are widely used in automatic signal processing systems, in digital photo and video recording systems and machine vision. The use of multimedia and television digital systems increases the urgency of solving the image reconstruction problems in the reconstruction of static and dynamic twodimensional signals. Reconstruction of images is an important area of application of modern digital information processing systems in obtaining a reliable estimate for visual and especially for automatic analysis. In most cases, when solving the reconstruction task, it is required to estimate the missing pixel values of images and video sequences, and also to select the most "similar" section from a large number of already existing ones. The solution of this task involves retouching and restoring of the missing fragments of images when removing scratches, defects, unnecessary inscriptions, etc.

Currently, the technical implementation of digital systems is intensively developing, their speed and energy efficiency are increasing. In this case, methods and algorithms for signal and image processing are used.

\section{Formulation of the problem}

As a practical example of the above discussion, let us consider the following problem, which has an applied character: the search and storage of space images in archives. In describing the digital images below, we will mean space images (SIs).

The task is to create a similarity search system (SSS) and to search for "similarity" in the archives of images storing WDFs based on Haar wavelet transforms and investigating this problem for stability [21-23].

\footnotetext{
${ }^{6} \mathrm{http}: / /$ window.edu.ru/resource/028/76028/files/PosobieERS.pdf

${ }^{7}$ http://files.lib.sfu-kras.ru/ebibl/umkd/54/u_course.pdf

${ }^{8} \mathrm{http} / / / \mathrm{www}$.dissercat.com/content/korrektsiya-tsifrovykh-kosmicheskikh-izobrazhenii-na-osnoveverifitsiruyushchego-modelirovan

${ }^{9} \mathrm{http} / / /$ www.dissercat.com/content/rekonstruktsiya-smazannykh-i-zashumlennykh-izobrazheniimetodami-regulyarizatsii-i-usecheniy
} 


\section{Basic concepts}

An important step in constructing a mathematical model of the concept of "similarity" for storing space images is the measurement of the appearance of the image boundaries using the Haar J-step discrete wavelet transformation (DWT) [13-15].

As it is well known, one of the problems in image processing is to find a way to efficiently represent an image or SI in a compact form. In modern practice of spectral analysis, recently acquired signals of a special kind, namely, wavelets have become quite popular. Since we are studying the SIs, we are primarily interested in two-dimensional discrete wavelet transforms. For being ascertained [16], the two-dimensional wavelet transforms are based on one-dimensional wavelet transforms that do not depend on the number of rows and columns of the image. By virtue of this rule, we consider, basically, the horizontal and vertical directions of the wavelets. Specifically, Haar's wavelets $[17,18]$.

1. These are piecewise constant functions defined on intervals having different scales and, furthermore, they take two values $\{-1 ;+1\}$.

2. The Haar's maternal wavelet, which has a unit scale and zero offset, is a function that takes the value +1 on the interval $[0 ; 1 / 2)$ and -1 on the interval $[1 / 2 ; 1)$.

The Haar transformation (HT) is one of the simplest basic wavelet transforms [19]. Let $f=f_{1}, \ldots, f_{N}$ - the one-dimensional discrete signal. The HT divides the signal into two components, the average and the difference. Suppose we have a sub-signal $a^{1}=\left(a_{1}, a_{2}, \ldots, a_{N / 2}\right)$ consisting of mean values. It is defined as follows:

$$
a_{n}=\frac{f_{2 n-1}+f_{2 n}}{\sqrt{2}}, n=1,2, \ldots, N / 2
$$

The detail signal $d^{1}=\left(d_{1}, d_{2}, \ldots, d_{N / 2}\right)$ at the same level is determined

$$
d_{n}=\frac{f_{2 n-1}-f_{2 n}}{\sqrt{2}}, n=1,2, \ldots, N / 2
$$

By means of these values, two new signals are formed:

$$
a=\left\{a_{n}\right\}, n \in Z ; d=\left\{d_{n}\right\}, n \in Z \text {. }
$$

The first of these signals represents a coarsened copy of the original, and the second is informative or detailed for the original signal.

$$
f_{2 n-1}=a_{n}+d_{n}, f_{2 n}=a_{n}-d_{n}, n \in Z \text {. }
$$


A similar partition can be performed with respect to the vector $a$. Let's consider an example with numbers. Let

$$
I=\left(\begin{array}{llll}
0 & 1 & 2 & 3 \\
4 & 5 & 6 & 7 \\
8 & 9 & 0 & 1 \\
2 & 3 & 4 & 5
\end{array}\right)
$$

Let us apply HT to the given matrix, using the principle of division by rows, thus we obtain the following matrix:

$$
\frac{1}{\sqrt{2}}\left(\begin{array}{ccccc}
1 & 5 & \vdots & -1 & -1 \\
9 & 13 & \vdots & -1 & -1 \\
17 & 1 & \vdots & -1 & -1 \\
5 & 9 & \vdots & -1 & -1
\end{array}\right)
$$

We apply HT to the given matrix, using the principle of column separation of the obtained matrix. We obtain the following:

$$
\frac{1}{\sqrt{2}}\left(\begin{array}{ccccc}
10 & 18 & \vdots & -2 & -2 \\
22 & 10 & \vdots & -2 & -2 \\
-8 & -8 & \vdots & 0 & 0 \\
12 & -8 & \vdots & 0 & 0
\end{array}\right)
$$

Or in general form we get the following matrix:

$$
\frac{1}{\sqrt{2}}\left(\begin{array}{ccc}
A & \vdots & H \\
\ldots & \vdots & \ldots \\
V & \vdots & D
\end{array}\right)
$$

$$
A=\left(\begin{array}{ll}
10 & 18 \\
22 & 10
\end{array}\right), H=\left(\begin{array}{ll}
-2 & -2 \\
-2 & -2
\end{array}\right), V=\left(\begin{array}{cc}
-8 & -8 \\
12 & -8
\end{array}\right), D=\left(\begin{array}{ll}
0 & 0 \\
0 & 0
\end{array}\right)
$$

Here

$A$ - area, including information about the global properties of the analysed SI;

$H$ - horizontal area, including information on the horizontal components of the analysed SI;

$V$ - vertical area, including information on the vertical components of the analysed $\mathrm{SI}$;

$D$ - diagonal component, including information on the diagonal components of the analysed SI.

When decomposing the image [20-24], the one-dimensional fast Haar transformation (FHT) is applied first to the rows, and then to the columns of pixel 
values of the input of the displayed matrix. As a result, we have a two-dimensional wavelet transform. As a result, the SI is divided into four equal parts LL, HL, LH, $\mathrm{HH}$ :

\begin{tabular}{|l|l|}
\hline$L L$ & $H L$ \\
\hline$L H$ & $H H$ \\
\hline
\end{tabular}

Fig. 2. Single application of a two-dimensional wavelet transform to a SI

LL - low-frequency wavelet coefficients (minor quadrant - reduced copy of the original image); $\mathrm{HH}$ - high-frequency wavelet coefficients. $\mathrm{N}$-fold twodimensional wavelet transform implies the application of $\mathrm{N}$ times the twodimensional wavelet transform to the lower quarter of the matrix - LL.

\begin{tabular}{|c|c|c|c|}
\hline$L L 3$ & $H L 3$ & $H L 2$ & \\
\hline$L H 3$ & $H H 3$ & $H$ & $H L 1$ \\
\hline$L H 2$ & $H H 2$ & \\
\hline \multicolumn{2}{|c|}{$L H 1$} & $H H 1$ \\
\hline
\end{tabular}

Fig. 3. Three-fold application of a two-dimensional wavelet transforms

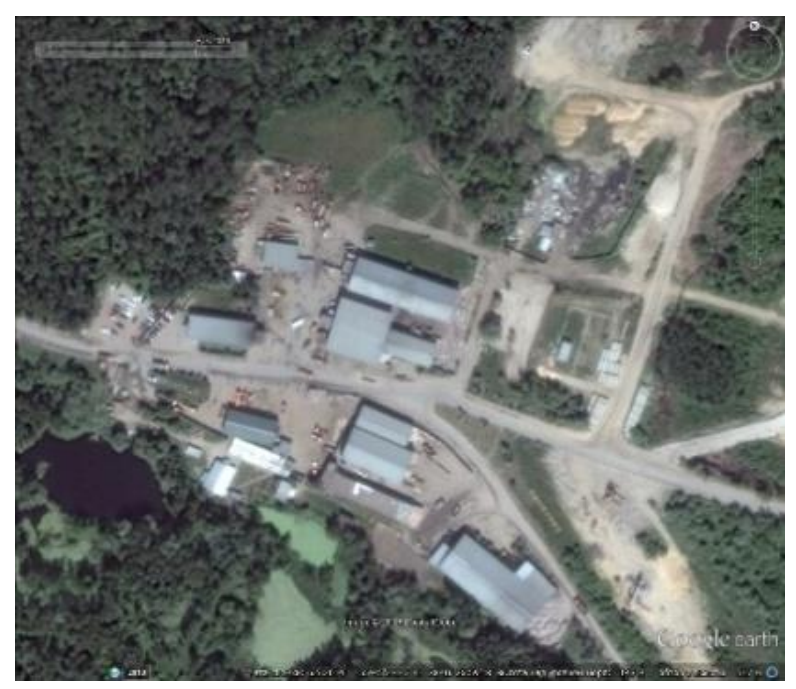

Fig. 4. The image of the landfill 
The inverse two-dimensional wavelet transform restores the lowest quadrant recursively. We take for the initial function of the space image, the image of the landfill (Fig. 4).

Consider a seven-step fibreboard using $\mathrm{db} 1$ (Haar). According to the structure, the database in which information on the waste disposal site (WDS) is stored [9] is presented as:

1. Common (name, type, location, comments, notes, etc.);

2. Geographical parameters (coordinates in different geographical projections, adjacent and including administrative-territorial units (AU), etc.);

3. Geometric (area, perimeter, litter concentration, accuracy of estimation, etc.) and other parameters.

Photographs and images, links to Internet resources, the degree of danger, the time of occurrence of $\mathrm{t} 1$ and the disappearance of $\mathrm{t} 2$ (their detection in images), notes are also included.

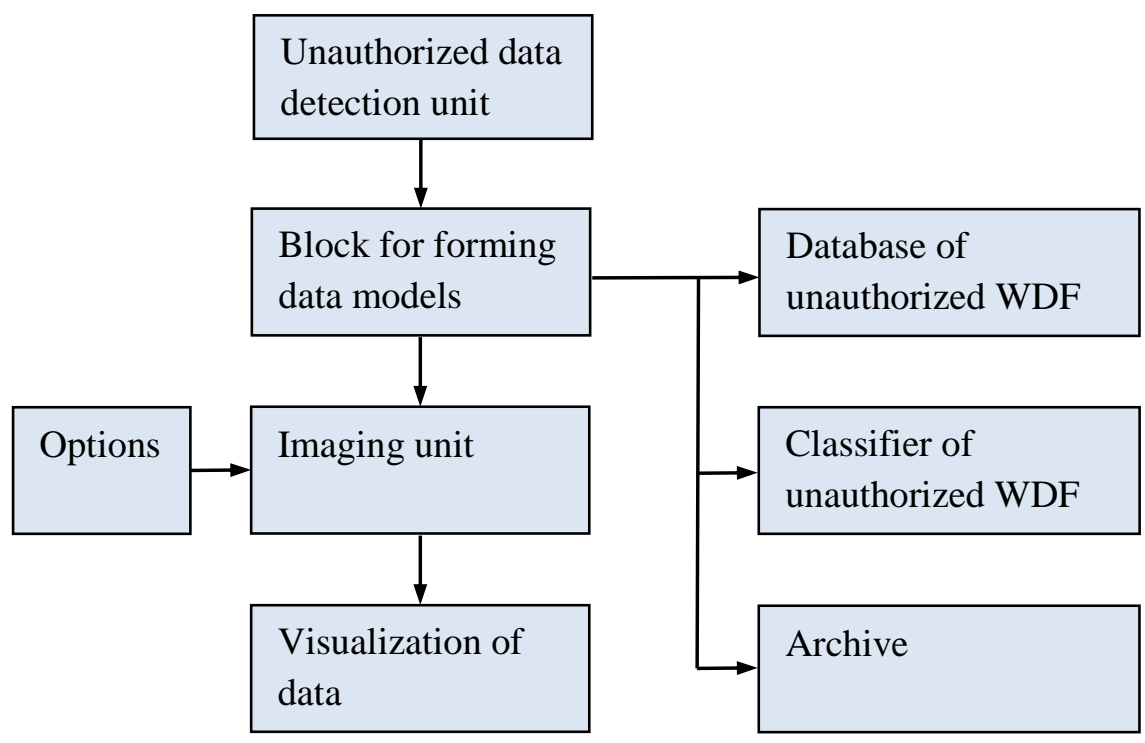

Fig. 5. Block diagram of obtaining a classifier and database of unauthorized WDS

Model of the WDS classifier is represented by the classification code as $\mathrm{X}$.Y, where $\mathrm{X}$ - classification code OKATO and $\mathrm{Y}=\mathrm{ZZZZ} \mathrm{-} \mathrm{WDS} \mathrm{sequence}$ number composed of limiting the hierarchy AU $X$ (unsaturated objects such as Balashihinsky district of Moscow region have $\mathrm{Y}=0000$ ). For a complete identification WDS injected additional code, identifying the WDS geographical 
location on the Earth surface in $\mathrm{AB}$ format, where $\mathrm{A}$ - latitude, $\mathrm{B}$ - longitude in HHHMMSS.SSSS format (HHH - degrees, MM - minutes, SS.SSSSS - seconds; 4 characters $S$ set the maximum geographical accuracy of detection). The classifier stores the current WDS, i.e. those that exist at the current time $t\left(t^{\prime}\right)$.

Each sequential WDS entered in the data model is assigned the sequence number $\mathrm{N}$, which connects the database, the classifier and the WDS archive. Historically, WDSs that have disappeared by the time $\mathrm{t}_{2}<\mathrm{t}$ are transferred from the classifier to the archive, with each new WDS assigned the next sequence number. The database stores information about all WDSs (current and historical). So, the principle of the SIs storing has been described above. The work in the database, storing the SIs, is carried out according to the following principle. Each SI is described in a text document containing administrative data (date, time of taking a picture, etc.). Also included are terms and phrases for key search. The documents found are linked directly to the snapshot, which can then be viewed. This is a normal, standard way of constructing a DBMS. However, to store the SIs this method does not provide a complete adequate description. Oral description of the SI, which must be found in the database, may not meet the expectations of the user. The archive, formed on this principle, does not allow the search for "likeness" of an image.

NGNs are systems that allow mechanisms to search for such images. They are relevant in connection with the active use of modern multimedia technologies. Hence, the purpose of the research is the development of the NGN project - the system for storing the SI, a description, and in particular, the WDS.

Thus, the database management system of the SI operates according to the following algorithm (Fig. 5):

- A space image is entered;

- A text document contains administrative information about the next digital image, i.e. date and time of image reception, then terms and phrases that characterize its content are entered, certain keywords are also input [9];

- Input the structure vector of the image.

Let $h, v, d$ be the horizontal, vertical, and diagonal components of the waveletHaar transformation of the original image or SI.

Definition 1:

The structural vector of the image $f$ is:

$$
x^{f}=\left(\sigma_{1 h}^{2}, \sigma_{1 v}^{2}, \sigma_{1 d}^{2}, a_{1}, \ldots, \sigma_{J h}^{2}, \sigma_{J v}^{2}, \sigma_{J d}^{2}, a_{J}\right),
$$


where $\sigma_{1 h}^{2}, \sigma_{1 v}^{2}, \sigma_{1 d}^{2}$ are the variances [13], $a_{j}=\frac{\sigma_{1 v}^{2}}{\sigma_{1 h}^{2}} \quad(j=1, \ldots, J)$ is the measure of anisotropy. If greater than 1, the structure is oriented vertically; if less than 1 , the structure is oriented horizontally.

Definition 2:

Let two pictures $f_{1}, f_{2}$ be given. Images $f_{1}, f_{2}$ are similar, if for, $\forall \varepsilon>0 \quad \rho\left(f_{1}, f_{2}\right)<\varepsilon$ where

$$
\rho\left(f_{1}, f_{2}\right)=\left\|x^{f_{1}}-x^{f_{2}}\right\|=\sqrt{\sum_{i=1}^{4 J}\left(x_{i}^{f_{1}}-x_{i}^{f_{2}}\right)^{2}}
$$

\section{Algorithm of similarity of two images}

Into the DBMS array of space images $f_{i} \quad i=1, \ldots$, both administrative data and structural vectors tied to the image are input. Let $g$ be the desired image and search for similar ones in the database are required. The query of the database is carried out according to the following principle:

- Calculation of the structural vector $x^{g}$;

- Sorting images $f$ of the database on the principle: $\left\|x^{g}-x^{f_{1}}\right\| \leq\left\|x^{g}-x^{f_{2}}\right\| \leq\left\|x^{g}-x^{f_{3}}\right\| \leq \ldots$. As a result, a "response directory" is formed;

- The recipient image directory $f_{1}, f_{2}, f_{3}, \ldots$ is given to the user.

To improve the qualitative set of the "response catalogue" it is necessary to use the procedure of "relevant feedback" in accordance with the following algorithm:

- Step 1. Let the user identify the first images of the recipient catalogue as relevant (suitable) or irrelevant (unsuitable). Denote by - most not suitable. Denote by - a set of suitable images;

- Step 2. A new search for similar images starts, for this purpose we introduce a new structural vector

$$
\begin{aligned}
& x^{\text {new }}=\frac{x^{g}}{\left\|x^{g}\right\|}-\frac{x^{f_{\text {mis }}}}{\left\|x^{f_{\text {mis }}}\right\|}+\sum_{f_{i} \in A^{\text {rel }}} \frac{x^{f_{i}}}{\left\|x^{f_{i}}\right\|}, \\
& \text { where }\left\|x^{g}\right\|=\sqrt{\sum_{i=1}^{4 J}\left(x_{i}^{g}\right)^{2}} ;
\end{aligned}
$$


- Step 3. The response directory is generated, viewed visually. If the result suits the user - Stop, otherwise go to Step 1.

\section{Investigation of the problem of searching similar satellite images on Tikhonov stability}

According to [14], we distinguish correctly defined and incorrectly defined problems. We give the notion of well-defined for the problem introduced by $\mathrm{J}$. Hadamard. The solution of any quantitative problem usually consists in finding a "solution" $\mathrm{z}$ from the given "initial data" $u, z=R(u)$. We shall regard them as elements of the metric spaces $F$ and $U$ with the distances between the elements $\rho_{U}\left(u_{1}, u_{2}\right), \rho_{F}\left(z_{1}, z_{2}\right) ; u_{1}, u_{2} \in U ; z_{1}, z_{2} \in F$. The metric is determined by the statement of the problem. So, let the concept of "solution" be defined as and to each element there corresponds a unique solution from the space $F$.

Definition 3:

The problem of determining a solution $z=R(u)$ from the space $F$ with respect to the initial data $u \in U$ is said to be stable on the spaces $(F, U)$ if for $\forall \varepsilon>0 \exists \delta(\varepsilon)>0$, from the inequality $\rho_{U}\left(u_{1}, u_{2}\right) \leq \delta(\varepsilon)$ follows that $\rho_{F}\left(z_{1}, z_{2}\right) \leq \varepsilon$, where $z_{1}=R\left(u_{1}\right), z_{2}=R\left(u_{2}\right) ; u_{1}, u_{2} \in U ; z_{1}, z_{2} \in F$.

Definition 4:

The problem of determining a solution $z$ from a space $F$ with respect to "initial data" $u$ from a space $U$ is called a metric space $(F, U)$ correctly posed on a pair if the following conditions are satisfied:

1. For any there exists a solution $z$ from the space $F$;

2. The solution is uniquely determined;

3. The problem is stable on the spaces $(F, U)$.

Tasks that do not meet the listed requirements are called incorrectly delivered.

\section{General algorithm of similarity of two images with regularizing matrix}

We give a mathematical formulation of the problem of finding similar images based on Haar wavelets using the regularization matrix. A two-dimensional wavelet transform is a one-dimensional, one-dimensional wavelet transform of rows and columns of this matrix. Firstly, one-dimensional wavelet transforms of each line are performed, after which the converted string is written to its original 
position. Elements are numbered. Next, wavelet transforms are applied to all columns. The image decomposition is shown in Fig. 2.

In general form, the similarity algorithm for two SIs has the following form: Let $X(i, j) i, j=\overline{1, \mathrm{~K}, N}$ be the original image or SI. The process of forming a distorted image can be represented as the output of some linear system. form:

The mathematical model of the process of forming a noisy image has the

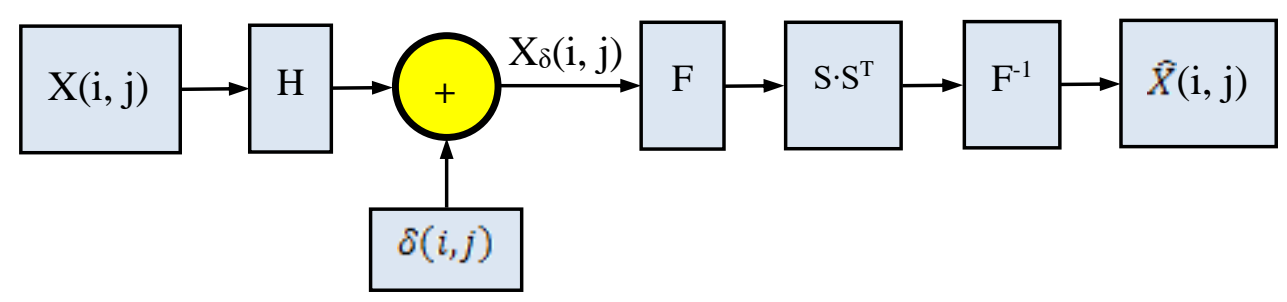

Fig. 6. Model of distorted image formation

The distortion process is modelled as a function of $\mathrm{H}$, which together with additive noise $\delta(i, j)$ acts on the original image of $X(i, j)$ and generates a noisy image $X_{\delta}(i, j)$

$$
X_{\delta}(i, j)=H[\mathrm{X}(\mathrm{i}, \mathrm{j})]+\delta(i, j) .
$$

The restoration of the image comprises the construction of the approximation $\tilde{\mathrm{X}}(\mathrm{i}, \mathrm{j})$ of the original image $X(i, j)$. The higher the approximation accuracy of the image $X(i, j)$ by the function $\tilde{X}(i, j)$, the more is known about the operator $H$ and noise $\delta(i, j)[13,14]$. A mathematical model for reconstructing a distorted image is an ill-posed task.

To conduct the experiment, consider a simplified version of the mathematical model:

$$
X_{\delta}(i, j)=\mathrm{X}(\mathrm{i}, \mathrm{j})+\delta(i, j)
$$

The problem of noise suppression consists of obtaining an estimate from the total observed signal, as close as possible to $X(i, j)$. We use the method of wavelet transforms with truncation of high-frequency parts of the spectrum using the Tikhonov regularization method. 


\section{Description of the algorithm}

We will carry out the experiment in the following way. Let's give a mathematical statement of the problem of removing non-informative pixels of the SI with regularization [13]. Let:

- $X(i, j) i, j=\overline{1, \ldots, N}$ be the initial image with data dimensions, considered as the result of some random process with certain properties;

- $F$ - discrete orthogonal transformation (Walsh, Fourier, wavelet-Haar, etc.),

- $F^{-1}$ - the inverse transformation;

- $S$ - a matrix of dimension choice $m \times N$ of rank $m, 1 \leq m \leq N$,

- $R_{\alpha}$ - a regularizing matrix in the task of processing the original image $X(i, j)$ defined as follows:

$$
R_{\alpha}=\left[\begin{array}{lllll}
\varphi(1, \alpha) & & & & \\
& \varphi(2, \alpha) & & & \\
& & \cdot & & \\
& & \cdot & \\
& & & \cdot & \\
& & & & \varphi(N, \alpha)
\end{array}\right]
$$

where: $\varphi(n, \alpha)$ are regularizing factors; $n=\overline{1, N} ; \alpha$ is a regularizing parameter.

The problem consists in choosing, for given $F_{0}, S_{0}$, a regularizing matrix $R_{\alpha}$ such that the following condition holds (where $\rho$ is a given metric):

$$
\tilde{X}(i, j)=F_{0}^{-1} S_{0}^{T} S_{0} F_{0} X(i, j)
$$

Comment: For a fixed transformation $F_{0}$, arbitrary matrix $S, R_{\alpha}=I$, this problem, known as the band coding problem by means of the transformation $F$, was studied in [6].

We present a general algorithm for compressing two-dimensional signals with a regularizing matrix $R$ :

- Step 1: the image of $X(i, j)$ is transformed to $F: Y(i, j)=F X(i, j)$, let $\delta(i, j)$ be white noise;

- Step 2: the matrix $\delta$ of the component approximations $Y_{\delta}(i, j)$ is replaced by the selection operator $S$ by a smaller vector $\tilde{Y}_{\delta}(i, j)$ that is to be transmitted over the communication channel, storage, etc. (the value $k=N / N_{0}$ is called the compression ratio). 
- Step 3: an "extrapolation" is carried out using the matrix $S^{T}$ i.e. on the receiving side, the resulting matrix is complemented to the dimension $N$ (for example, all components except those selected are assumed to be 0 ).

- Step 4: the resulting matrix undergoes an inverse $F^{-1}$ transformation;

- Step 5: Multiplication by a matrix of regularizing factors $R_{\square}$ is carried out.

As a result of these steps, the original vector is restored with errors:

$$
\varepsilon 1=\rho_{l_{2}}\left(X(i, j), F^{-1} S^{T} S F \tilde{X}_{\delta}(i, j)\right), \quad \varepsilon 2=\rho_{C}\left(X(i, j), R_{\alpha} F^{-1} S^{T} S F \tilde{X}_{\delta}(i, j)\right)
$$

The problem consists in choosing $\alpha$ and therefore $\varphi(n, \alpha)$ so that for the given $k$ the following condition is satisfied: $\varepsilon 2<<\varepsilon 1$. The choice of $\alpha$ and $\varphi(n, \alpha)$ for the corresponding orthogonal transformations depends on the input data and the transformation structure. The form of the matrix $R_{\alpha}$ is defined for the continuous case and is used in a discrete interpretation of the image compression problem with regularization. Table 1 gives a specific form of the matrix $R_{\alpha}$ for various transformations.

Table 1. Specific form of the matrix $R_{\alpha}$ for various transformations

\begin{tabular}{|l|l|l|c|}
\hline Fourier & $\varphi(\alpha, k)=\frac{1}{1+k^{2} \alpha}$ & $k=\overline{1, \infty}$ & [6] \\
\hline Walsh & $\varphi(\alpha, k)=\frac{1}{1+k^{p} \alpha}$ & $k=\overline{1, \infty} ; \quad p>1 / 2$ & [6] \\
\hline Wavelet Haar & $\varphi(\alpha, k)=\frac{1}{1+(\alpha k)^{\lambda}}$ & $k=\overline{1, \infty} ; \quad \lambda>1 / 2$ & [6] \\
\hline
\end{tabular}

The table does not indicate the exact values of $\alpha$. The question arises of determining the values of $\alpha$, for which the conclusions of the experiment are valid. The specific value of the regularizing parameter $\alpha$ is determined experimentally and is given in Table 2. Here, $\alpha_{1}$ is the lower bound; $\alpha_{2}$ is the upper limit of the change $\alpha$.

Table 2. Experimental specific values of the regularizing parameter $\alpha$

\begin{tabular}{|l|l|l|l|l|}
\hline & COS & WAVELET-HAAR & WALSH & FOURIER \\
\hline 0.5 & 0.99 & 0.5 & 0.99 \\
\hline 0.00005 & 0.000001 & 0.000001 & 0.000001 \\
\hline
\end{tabular}


A chart is shown on Fig. 7 where the arrangement of compression errors with regularization $\varepsilon 2$ and without regularization $\varepsilon l$ for the average experimental parameters is presented.

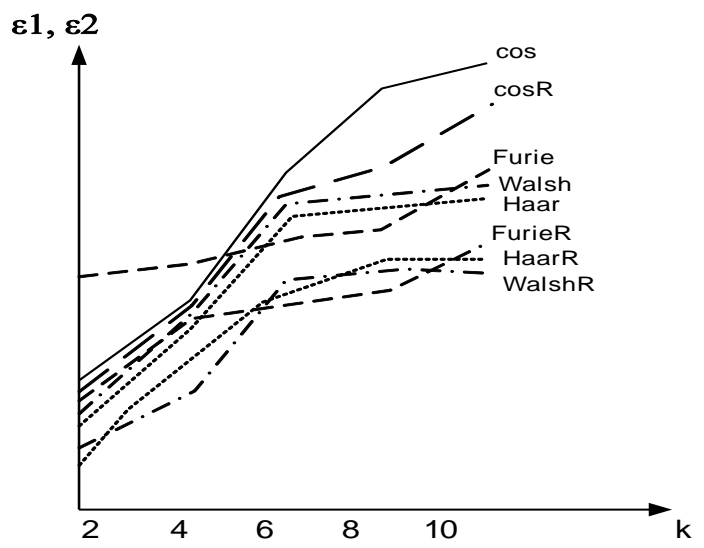

Fig. 7. Compression errors with regularization and without regularization for averaged experimental parameters

\section{Conclusion}

The project to create an automated space monitoring system for the presence of a WDS on the territory of the Russian Federation, designed to provide an operative survey of the studied area, the detection and mapping of real and potential foci of unauthorized dumps, the forecast of their development, a preliminary assessment of the scale of disasters and possible consequences is of great urgency. The current article explores the project model. The use of the data warehouse in the task of space monitoring of the WDS enables not only improving of the performance of environmental authorities, but also to enhance the monitoring effectiveness of the WDS (space, aerological and terrestrial).

\section{References}

1. Aristov, M. A. Monitoring of solid waste landfills and detection of spontaneous garbage disposal according to space survey data. GeoProfil.ru. № 2. http://internetgeo.ru/ uploads/ journals/geoprofile0209/monitoring_tbo.pdf

2. Pogorelov, A. V., S. V. Dulepa, D. A. Lipilin. Experience of space monitoring of landfills in the territory of the Krasnodar Territory. Geomatika 2013, № 4, pp. 6471. http://geomatica.ru/pdf/2013_04/2013_4_64-71.pdf 
3. Avetisyan, D., R. Nedkov. Determining the magnitude and direction of land cover changes in the semi-natural areas of Haskovo Region, Southeast Bulgaria. Geoscience and Remote Sensing Symposium (IGARSS), 2015 IEEE International, IEEE, 2015, pp. 4637-40. DOI:10.1109/IGARSS.2015.7326862.

4. Stankova, N., R. Nedkov. Monitoring forest regrowth with different burn severity using aerial and Landsat data. Geoscience and Remote Sensing Symposium (IGARSS), 2015 IEEE International, IEEE, 2015, pp. 2166-69. ISBN:978-1-4799-7929-5, ISSN: 2153-7003, DOI:10.1109/IGARSS.2015.7326233.

5. Stankova, N., R. Nedkov, I. Ivanova, and D. Avetisyan. Integration of multispectral and SAR data for monitoring forest ecosystems recovery after fire. Proc. SPIE 10444, Fifth International Conference on Remote Sensing and Geoinformation of the Environment (RSCy2017), 104441J, 10444, SPIE, 2017, ISBN:978-9963-697-243, DOI:10.1117/12.2277313

6. Nedkov, R. Quantitative assessment of forest degradation after fire using ortogonalized satellite images from Sentinel-2. Comptes rendus de l'Academie bulgare des Sciences, 71, 1, publishing house of BAS „Prof. Marin Drinov“, 2018, ISSN: 2367-5535

7. Nedkov, R. Normalized differential greenness index for vegetation dynamics assessmenT. Comptes rendus de l'Academie bulgare des Sciences, 70, 8, Prof. Marin Drinov Publishing House of Bulgarian Academy of Scinces, 2017, pp. 1143-46, ISSN:1310-1331.

8. Panayotova, D., R. Nedkov, M. Dimitrova, I. Ivanova, and M. Zaharinova. EcoMonitoringal Investigation of Forest end Land-Used Area and Agro-Climate Characteristics in the Land of the Municipality of Kardzhali, Using Aerospace and GPS Data. Journal Biotechnology \& Biotechnological Equipment Volume 23, 2009 - Issue sup1: XI Anniversary Scientific Conference, 23, sup1, Taylor \& Francis, 2009, ISSN: 1310-2818, pp. 200-03, DOI:10.1080/ 13102818.2009.10818400

9. Avetisyan, D., R. Nedkov, E. Velizarova, and D. Borisova. SAR and optical data in land degradation processes estimation: a case study from Southeast Bulgaria. Proc. SPIE 10428, Earth Resources and Environmental Remote Sensing/GIS Applications VIII, 10428, SPIE, 2017, pp. 104281D-1-104281D-9. ISSN: 0277786X, DOI:10.1117/12.2277945.

10. Aleksandrovna, L. N., M. L. Glinsky, A. A. Zubkov, V. V. Danilov, and L. G. Chertkov. Monitoring of the state of the subsoil on the LRW burial site. http://www.atomic-energy.ru/articles/2012/02/20/31086

11. Brovkina, O. V. Remote monitoring of anthropogenic disturbances in the taiga zone of the Northwest of Russia. PhD dissertation, 2011, $125 \mathrm{p}$.

http://www.dissercat.com/content/distantsionnyi-monitoring-antropogennykhnarushenii-taezhnoi-zony-severo-zapada-rossii

12. Yannikov, I. M., M. V. Sleptsova, and K. K. Krivoshapkin. Organization of biomonitoring of chemically hazardous objects and landfills with the use of identification polygons. Bulletin of the North-Eastern Federal University. M.K. Ammosov, NEFU, Yakutsk, 2013. pp. 15-25. http://cyberleninka.ru/ article/n/organizatsiya-biomonitoringa-himicheski-opasnyh-obektov-i-poligonovtbo-s-ispolzovaniem-identifikatsionnyh-poligonov 
13. Kazaryan, M. L., M. A. Schahramanian, and A.A. Richter. Space monitoring of the Earth and Haar wavelet transform. Future Communication Technology and Engineering, Chapter 61, Edited by Kennis Chan CRC Press 2015, pp. 291-94. Print ISBN: 978-1-138-02777-0. eBook ISBN: 978-1-315-69045-2. DOI:10.1201 / b18331-65

14. Kazaryan, M. L., M. A. Schahramanian, and A.A. Richter. Multidimensional Haar wavelet-transient research on the stability in the context of a satellite monitoring of the Earth problem//Serbian journal of electrical engineering (in press)

15. Kazaryan, M., M. Shakhramanyan, R. Nedkov, A. Richter, D. Borisova, N. Stankova, I. Ivanova, and M. Zaharinova. Research of the generalized wavelet transformations of Haar correctness in remote sensing of the Earth//Proc. of SPIE Vol. 10427-74 (Conference 10427: Image and Signal Processing for Remote Sensing Conferences: 11-14 September 2017, Warsaw, Poland), p. 99. https://spie.org/ERS/conferencedetails/image-signal-processing-remotesensing\#227857

16. Richter A. A., M. L. Kazaryan, M. A. Shakhramanian, D. Borisova, N. Stankova, I. Ivanova. Information modeling of waste disposal sites. Ecological Engineering and Environment Protection, 1, 2017, pp. 15-21, URL: http://ecoleng.org /archive/2017/1/15-21.pdf

17. Chui, C. K. Wavelets: A Mathematical Tool for Signal Analysis. SIAM, Philadelphia, 1997.

18. Daubechies, I. Ten Lectures on Wavelets. SIAM, Philadelphia, 1992.

19. Gonsales, R. C., R. E. Woods, S. L. Eddins. Digital Image Processing using Matlab, Pearson Prentice Hall, Upper Saddle River, NJ, 2004.

20. Korolyuk, V. S., N. I. Portenko, A. V. Skorokhod, A.F. Turbine, et al. A handbook on probability theory and mathematical statistics. M.: Science. The main edition of physics and mathematics, 1985, $640 \mathrm{p}$.

21. Tikhonov, A. N. and V. Ya. Arsenin. Methods for solving ill-posed problems. M.: Science. Home edition of physical and mathematical literature, 1979, $288 \mathrm{p}$.

22. Mallat, S. A wavelet tour of signal processing. N. Y.: Acad. Press, 1999, 851 p.

23. Nedkov, R. Orthogonal transformation of segmented images from the satellite Sentinel-2. Comptes rendus de l'Acad. bulg. des Sciences, 70, 5, Prof. Marin Drinov Publishing House of Bulgarian Academy of Sciences, 2017, ISSN:13101331, pp. 687-92.

24. Anuj, B. and A. Rashid. Image compression using modified fast Haar wavelet transform. World Appl. Sci. J. 2009. 7, 5. pp. 647-53. 


\title{
ИЗСЛЕДВАНЕ НА СТАБИЛНОСТТА НА АЛГОРИТЬМ ЗА ПОДОБИЕ, ИЗПОЛЗВАН ВЬРХУ СИСТЕМА ЗА СЬХРАНЕНИЕ НА СПЪТНИКОВИ СНИМКИ ЧРЕЗ ХААР УЕЙВЛЕТИ, СПОРЕД ТИХОНОВ
}

\author{
М. Казарян, М. Шахраманян, С. Забунов
}

\section{Резюме}

Дистанционните изследвания на Земята позволяват получаването на информация със средна до висока пространствена разделителна способност от космически летателни апарати, с хиперспектрални инструменти на борда.

В настоящата статия е разработен модел на автоматизирана система за откриване на сметища чрез космически наблюдения (АСОС). Един от компонентите на модела е модулът за съхранение на космически снимки, който позволява не само да се подобри ефективността на институциите, занимаващи се с опазване на околната среда, но и също така да се увеличи производителността на мониторинга на сметища, базиран на космически изследвания, въздушни наблюдения и наблюдения от Земята. Освен това се изследва проблемът за търсене на подобия в архиви с космически снимки чрез използване на Хаар уейвлет трансформацията за стабилност.

Тук се използва регуляризационният метод на Тихонов, елементи на математическия анализ, теория на дискретните ортогонални трансформации и методи за декодиране на космически снимки.

Научна новост в разработката е предложеният модел на автоматизирана система за космически мониторинг, предназначена за откриване на сметища. Задачата за обработка на архивирани космически снимки, и поконкретно тьрсенето на подобия в архивите от космически снимки, е изследвана от гледна точка на некоректно дефинирана задача. 